\title{
Dissection on the Current Sustainability Concepts
}

\author{
Komal Dwivedi ${ }^{1}$
}

\begin{abstract}
The paper deals with a cluster of perspectives upon the revolving concepts of the sustainability in economic, cultural and most importantly the environmental sphere. These concepts correlate economy with the environment and its general components that we are composed of or which facilitate our day to day living. The absurdity of the human actions has shifted the question mark from development to survival. The mankind needs a general yet specific and effective mechanism to maintain the round ball as a life supporting planet. The research has its major concern over the corelation of the spheres for the effective working of the model of sustainable development. The spheres are interdependent on each other for their existence. The analysis has been done on the basis of the Brundtland report. The research deals Formulation of different guidelines for different member nations with consideration of the European Union perspective. The research brings out the essence of the three essentials of sustainable development optimum utilization of resources, no wastage of resources and preservation of resources. There also have been perspectives on possible growth and development described in the research.
\end{abstract}

\section{Introduction}

Sustainability is a concept which throws lights upon a generic term known as sustenance, which in literal terms means anything that can last long, sustainability remains to be a process of transforming anything into a class where it can be maintained as well as can be manifested with determinate existence and such sustenance brings out stability, advancement, deliverance and a chance of developmental process to excel. This process is what is the current need of the hour, the process demands certain changes to the existing concepts of sustainability and in return brings out positive changes in the current spheres which include economic and environmental spheres. Relating concepts of the economy with the environment can make tasks of achieving sustainability easier as these are core elements of human existence and are the sole foundations that could possibly answer the current questions upon the sustainable development concepts and their implications. The concept of sustainability with reference to economy and environment relates to bringing out a subtle story of the interdependence of the two concepts with each other with due stability, endurance, material structure, sustenance and dynamic power to excel with developmental changes. The basic idea of interdependence stands as the integral foundation of the structure of sustainable development of all spheres.

The two concepts are capable of transforming the third sphere that is the cultural one into a base which would be free of all atrocities, all cultural differences and could possibly remove all question upon the human existence that has been put forward due to the ignorant attitude of the mankind towards the ecosystems and its maintenance needs. 
The fact of implementing the sustainability as a model in the human and ecological relationship stands a challenge to the mankind as the present scenario speaks of horrible conditions of the ecosystems that have been maintained with utmost care and have posed a major threat to the human existence. The basic problem remains to be the creation and maintenance of a uniform model of sustainability that could be implemented all around the globe.

The main focus should be the interlinking of all the spheres for the indicative uniform sustainable process to work and also to maintain the ecosystem and to sustain it. The differences should also be kept in mind while determining a uniform system because these differences relate to a difference in economic structure, the difference in resource distribution, difference in status of laws and statutes.

The emerging trends suggest a uniform law code that stands unified as well as well differentiated for different nations as per their laws and economic scenes. The implementation of such code is a must to reach the level of sustainable development.

\subsection{Origin and History}

The word sustainable was visible for the very first time in the 20th century in the oxford dictionary after which many political thinkers and well-known jurists gave their comments on the emerging global trends in the biological sphere which paved way for various discussions regarding the idea of sustainable development. Around the nineteenseventies, the expectations from the words growth, development, and progress were making a chaos as the definitions of development were quite contradictory as some people were ready for development at the cost of the ecosystem whereas some still knew the importance of it and were ready to remain underdeveloped.

The period after the industrial revolution marked two lines in the history, one was the drastic growth in the production and the consumption sector. The other bold black line in the history was the enormous depletion of resources that occurred as a result of the ignorant human behavior and the never ending thirst of creating wealth. This made the idea of sustenance a much relevant solution towards the growing problem of pollution and resource depletion.

The concept of sustainable development formed the basis of the United Nations Conference on Environment and Development held in Rio de Janeiro in 1992(Daly, H. E. (1990)). The first ever official definition came from the well known Brundtland report that made foundations to the pillars environmental development 'Sustainable development is a development that meets the needs of the present without compromising the ability of future generations to meet their own needs'. Brundtland Report, WCED(Seuring, S., \& Müller, M. (2008).

\subsection{Concept}

The conceptual base in the picture of sustainable development is that it seeks for the preservation of resources with minimum wastage and their optimum utilization. These demands interrelate to each other as one can be achieved by fulfilling the other one. The process of careful use of resources with a mind to preserve them and for the future minds to do the same and to make it an endless process with using the present resources to an optimum level to attain maximum for the mankind. 
The main intention behind the approach of preservation is the mere maintenance part that has been missing all this while. The questions upon the ruthless behavior of the mankind towards the ecosystem that yet stands as the answer to these lives resembled baseless with the front arguments stating that the quality followed by the human need is that they could never end posting an undying potential to stab knives over the environment yet again. The only conceptual flaw or rather a misunderstood part is that sustainable development concepts are not applicable or lack relevance with some ecological or environmental problems, some of which could be a major issue for some regions. However, the truth yet remains unrealized as this particular concept has a lurking capability to resolve almost all environmental issues may it be resource depletion or anything relevant. The concept demands domination over the unceasing needs of humankind on earth and in return gifts a better place to live in and to sustain life for all long.

The studies on the subject reflect a circle of a cocoon which suggests that the early care of nature reminds a necessity to curb the harm caused by the frequent human interference as far as the care is regarded it is quite necessary so as to protect mankind of all the possible threats.

Sustainable development concepts are the most relevant and accurate solutions to the present environmental problems. These concepts vary from issue to issue as it presents a set of options or rather alternative options for all human needs, for instance, the use of fuels that emit energy, which can be further recycled and reused.

\subsection{Sustainability and development}

Development is a narrative term and also its meaning is incomplete without two terms one being the Extent and the other is a positive change. The development could be the height of positive changes made towards implementing an idea for better lives and that could economically feasible.

The following equation presents a downline clue to sustainable development.

\section{$(\mathrm{x}=\mathrm{o}+\mathrm{m}+\mathrm{p})$}

- Where $\mathrm{x}=$ The level of sustainability to be attained

$\mathrm{o}=$ optimum level of utilization

$\mathrm{m}=$ minimum wastage level

$\mathrm{p}=$ preserving of resources

This chair model presents a cluster of blocks that are required to build a castle as these stand as the foundation blocks behind the castle of sustainability. The words relate to a parallel state where sustainability goes hand in hand with all the above given situational factors, which is further explained through a process.

\subsection{Process of sustainable development}

- Crossline perspective

This perspective is an imaginary base where the assumption follows as -:

1. The country has an underdeveloped structure of development

2. The perspective is used to work on the situation

3. The crossline perspective assumes that the country has a normal level of resource availability 


\subsubsection{Procedural base}

The process will begin from the roots of the structural base.

Stage 1: Categorizing of resources into various types and their usage levels on the basis of priority.

1.2: Realizing the potential spheres which can initiate the developmental process.

1.3: Sketching out all the economic differences and cultural differences.

1.4: Initiating the basic developmental flight.

Stage 2: Creation of laws that facilitate economic credibility without interfering with the base laws of the country and disturbance to economic credibility.

2.1 Maintaining a bridge gap between the development issues and ecological ones.

2.2 Proper checking on the dynamic needs of the laws and principles of an ecological sphere.

2.3 Connecting the links between the various sects of the economy

Stage 3: Following all of these in the policy making process

* Optimum utilization of resources

* No wastage of resources

* Preservation of resources for the future

\subsection{Environmental law principles}

The principles which process law into a circle of ecology. Environmental law is a branch which relates to protection and maintenance of the ecosystem while preserving the interests of the mankind.

These principles deal under three heads-:

- Rules

- Concepts

- Principles

The core concept of any environmental law is followed through a process of certain rules that bind the law and then certain principles which strengthen it, followed by a conceptual base for its formulation.

\subsection{The Sustainable Development Principle}

The principle of environment law which deals with all possible situational factors which result into two formational sections

\section{$>$ Economic development}

$>$ Environmental protection

The major focus of the principle lies in achieving the two objectives together and maintains equal concern for both of these.

Economic development is concerned with the proper working of the economic cycle and that the three components of an economy are well developed which are Production, Consumption, and investment. Production well relates to the problem of depletion of resources as it acts as the main source for the generation of the problem, this is where the sustainable development principle works as it maintains equity between the economy and the ecosystem.

Environmental protection, on the other hand, is a varied concept that relates to the protection of the ecosystem from all possible threats raised by mankind. Man makes use 
of almost everything to satisfy his never ending needs, but what is being sacrificed in gaining that satisfaction is the headline which has been missing out all this while. The man has to know the limits where he needs to constrain his moments.

The concept of utility derivation is the answer towards the subtle idea of constraining human moments towards the end of mankind. Utility in a depth study proves out to be an urge to gain more and more of something which can satisfy however the myth of satisfaction derivation does not prove its existence and hence cannot be relied upon. This also is an undeniable fact that utility is something which is to be achieved but cannot be achieved as it makes thirst to gain more and more. However, this maybe something which can be overlooked but the reality uncovers that the only truth behind growing human consumption is the population which has grown limitlessly over the past years that needs to be gained concern on.

The sole behind the ultimate change thought of is strong laws with better implementation and ideas of sustenance in the developmental process. Laws are not the lead actors in the story instead the human behavior influenced by the human mindset paves way for changes to occur.

The principle is an epitome of the renowned models grabbing attention of the environmentalist but yet remains to be under curtains waiting for its turn to come on the stage and takes its place which it deserves, the irony on the state is that the realization hasn't yet taken place that the mankind is in need of the implementation of the principle. There is an immediate need of considering this principle in the policy and law-making process as this could act as the first aid to the persistent harm that has been caused to the planet which in return has made situations bizarre and complex in nature.

\section{- Precautionary principle}

The principle deals with the sorted theory of precautions and that guide us to differentiate between the priority alerts and the other compromisable ones, however, the principle is only concerned with the priority admonitions which are of great danger to the human population.

It is based upon four sources -:

* Immediate action towards minimizing the harm caused

* Tracing all possible alternatives available

- Deciding the degree of harm with consideration on the future consequences

* Critical examination of all the possible threats that need to be eliminated

\section{- Integration principle}

The perspective of this principle showcases it as a principle underlying the major focus on the conservation and preservation but together with it relates it to development rather than isolation.

\section{Ecology, Economy, and Culture}

The dominion follows the sense of development with relevance. The arguments upon these connecting sections completely satisfy the extremity of the cause. The thought behind their interdependence has been sensible enough as it suggests on the needs they correlate with each other. Their interdependence, however, has been of great 
advantage as these make development and protection easier. The content of these three worlds is solely based on human existence, however, one involves the existence of both flora and fauna. Past years resemble a story of great development in the global economy due to globalization.

\subsection{Development in culture}

Culture is the effectuation of all intellectual regards that a man is known for. Cultural development expedites on to the relational reciprocation of knowledge, ideas, substantial base of different subjects, underlying assumptions, and makes the aridity of inquisitiveness to discontinue.

Culture has been important to the man from the earliest of times as that is something that each man could find relevance with. The inter-linking between cultures has minimized the differential gaps between economies and cultures and hence globalization has proved to be fruitful. The utmost careful evaluation on the expansion of economies is a far debatable topic that structures the arguments upon globalization and the cultural feasibility that has paved the way for open and free mindsets to some extent.

Cultures extend a hand through to leave the world in hands of better. This exchange of cultures does not only facilitates us with the ultimate knowledge but also creates a vicious circle of inclined economies and flourished cultural diversities. These concepts are well versed and are an established facts in the eyes of governance and hence the cultural exchange takes place at the very certain level through students, visitors and many more advanced sects are employed in the working of the same.

\subsubsection{Cultural development and its relevance to human development}

Human development is the outcome of cultural development which invites the source of human behavior, and also extricates the valuable history and legacy of man from decadence. It is fascination and meddlesomeness that has made the development of the sector that created remarkable changes in the past years that yet stand as the edifice of human existence and its social and cultural heritage.

The evident facts that present humans of a convivial order and however absolves the existence and the process of evolution that defines the diversification and allows it to continue further.

The concept of inter-linking the cornerstones of the mankind' living setup can be far useful to change the situation of the present environment. The proposal of the interconnection of culture with a subtle blend of the economic and ecological part sounds quite convincing for the increasing concern towards the survival of the mankind. The story begins from including ecological concern section in every sector relevant or related to the developmental process, be it the production stock or the infrastructural sphere anything that is to lead man to satisfaction and fulfillment of a major law abiding need is to be guarded by the clause of environmental concern. 


\section{Finalized Concept of Sustainable Development}

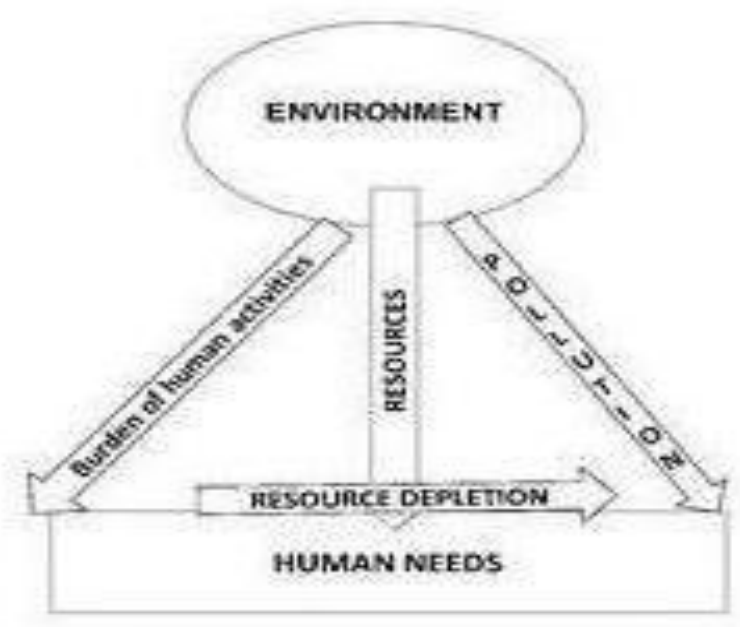

Figure 1. The structure of the problem

This is the base problem for which the cure stands as the sustainable development which takes the two cores together in working without affecting the other one adversely with an equalized concept of development.

The structure speaks of a process where the root cause is the unending needs of the human in relation to the fulfillment of those needs through nature. Following is a root cause that initiates the problem to reach a questionable level:-

- Never ending human wants

- Growing population

Problems relevant to the source of scarcity also creates the ground for two natural structured problems one defining the nature and the other defining a prolonged activity.

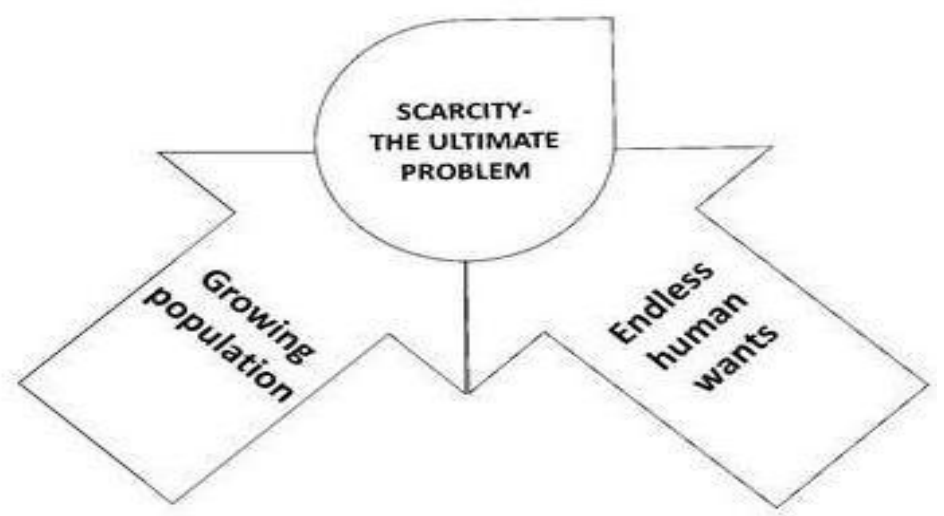

Fig. 2. The root cause 
The basic problem is initiated through the two above given root causes which are the obvious reasons for the disturbed environmental conditions driving humans to a moat that would eventually lead to death.

Human wants are naturally endless by nature and have low chances of change but one problem which could be treated is the growing population. This is the quite obvious answer to human survival.

\section{Conceptual Analysis}

The subaqueous scrutiny of the front sections deals with the ultimate souls of the serene environment and the economic criterions that are obvious to be fulfilled. The concept implies the inclusion of the sustainable concepts into the economic spheres with natural environmental concerns.

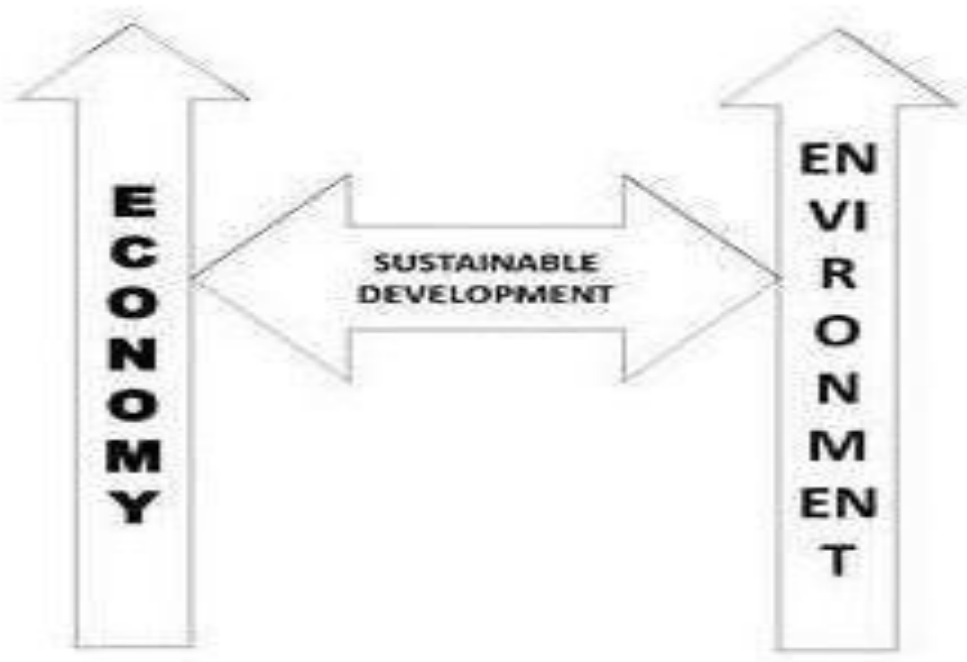

Fig.3. The ultimate solution

The economic structure in parallel states goes hand in hand with the environmental sphere to attain the optimum level of the developmental process. The world of the ecosustainity needs the foreground of various environmental solutions and also prepares the mankind to enhance the capability of the environmental sustenance. The field of the leveled process underlines the sectional depth of the process and frequent environment problems.

\section{Eradication of the problems}

The problems demand solutions and in the current case, the solution is the eradication of the root problems. 


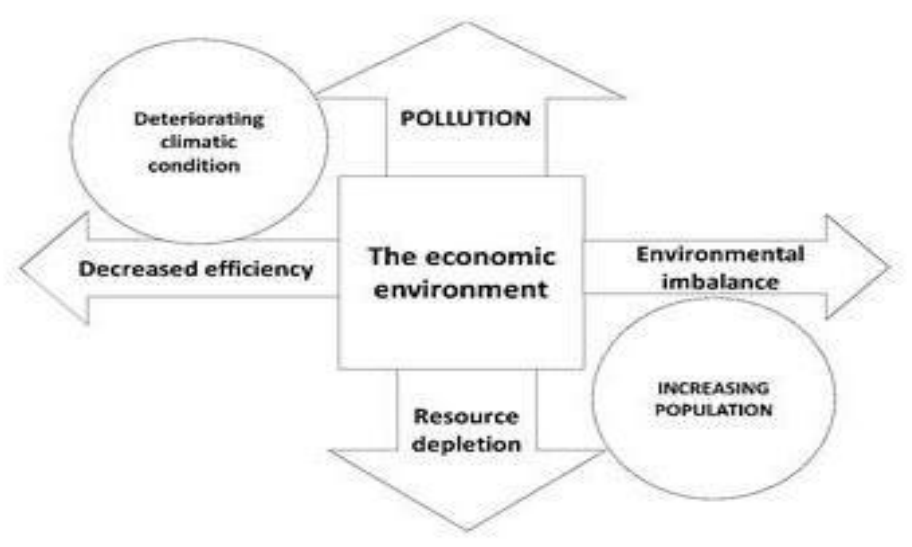

Fig.4. Economic-environmental problems

The basic problems that relate to economy and environment are described above and also which act as obstacles in the way to development, moreover, the subjects of the economy fall relevant to the subservience of environment.

Economy counts as the environment processes itself into fruitful stuff that could possibly indemnify the aridity of the human wants. The valuable stuff, however, hasn't yet gained the importance in human eyes.

\section{Formulations of Various Guidelines for Attaining Sustainable Development for all Nations}

The research paper has depicted formulations for all member nations to attain the optimal level of sustainable development:-

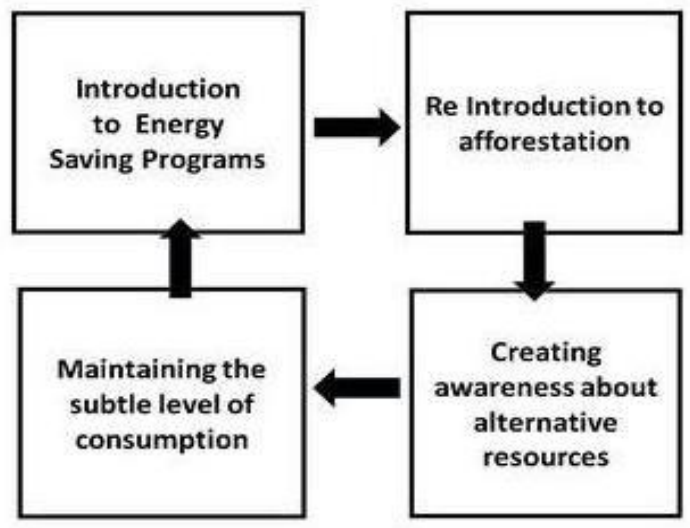

Figure 5. The possible combination of guidelines 
The variations that different countries have in terms of area, the availability of resources, the strength of the economy, the currency power, the population count they hold makes it necessary for them to vary in terms of policy making too because policy making process involves evaluation of all these criterions which stand as foundation variables in making development process possible.

The use of Efficient Energy Alternative Resources (EEAR) that refers to all those alternatives that can be made into use instead of using the normal sources of energy, for instance, the using of coal as an energy option for the production of electricity could be avoided and use of hydroelectric energy or tidal energy or even geothermal energy could be put into use.

\subsection{Alternative sources of energy}

These are the sources which generate energy and fall as alternative options as they come with the guarantee of durability, feasibility, and also which is suitable accordingly. These resources can be reused for $\mathrm{n}$ number of times and also they are environment-friendly which makes them more favorable.

\subsubsection{Hydroelectric Energy}

Flowing water creates energy that can be captured and turned into electricity. This is called hydroelectric power or hydropower(Nakon, E. (2017, April 7)). This is one among the most widely used source of energy and has been accepted worldwide as a concept that is used for electricity generation. The use of this energy source provides for various benefits such as economic feasibility as the water is available free of cost and the reusability is a clause which makes it more favorable.

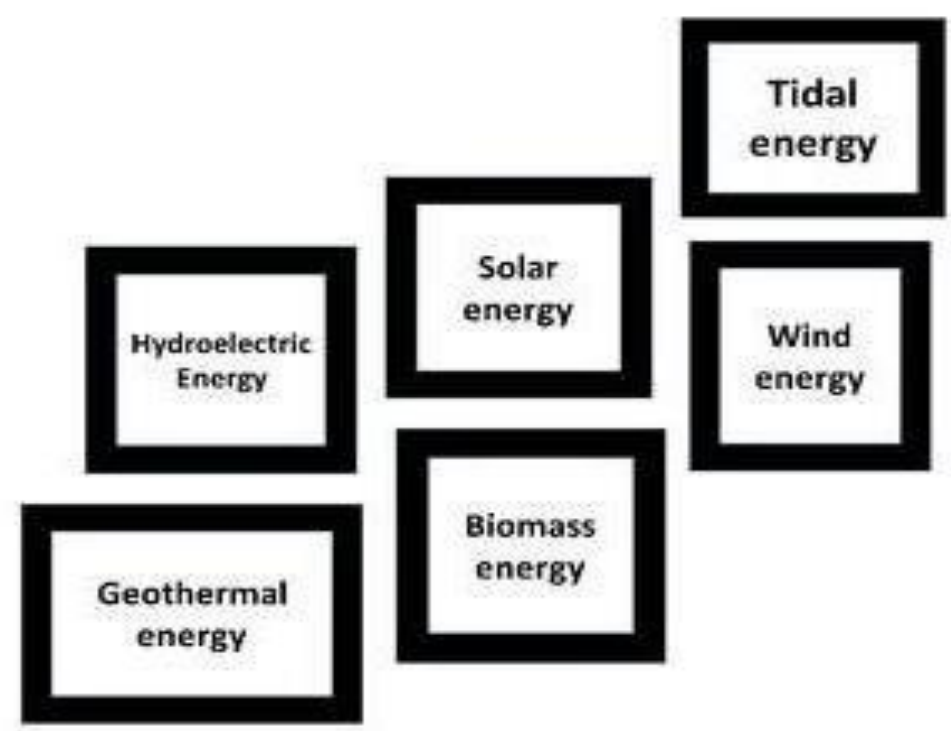

Figure 6. Various alternatives available 


\subsubsection{Geothermal energy}

The energy that is derived from the heat of the earth's crust that escapes through the hot water springs which are further transformed into various energy needs of the mankind such as in the United States, most geothermal reservoirs of hot water are located in the western states, Alaska, and Hawaii and Wells can be drilled into underground reservoirs for the generation of electricity while, some geothermal power plants use the steam from a reservoir to power a turbine/generator, on the other hand, using hot water to boil a working fluid that vaporizes and then turns a turbine is also normal, the hot water near the surface of Earth can be used directly for heat the best advantage is the direct-use applications include heating buildings, growing plants in greenhouses, drying crops, heating water at fish farms, and several industrial processes such as pasteurizing milk(M. (1979))

\subsubsection{Biomass energy}

This energy is one of the very basic energy available to mankind as it is very readily available to the man with a very subtle chemical conversion reaction between carbon dioxide, water and sunlight through a process called as photosynthesis. This reaction makes biomass energy available to humans.

\section{European Union Perspective}

The European Union laid its first ever strategy on the sustainable development issue in the year 2001. The European Union had involved two distinct features one was the foundation to the issue that subsisted of the policies and the ulterior motives behind its creation.

Earlier there had been the monopolistic approach towards the economic and environmental development that was majorly owned by the Lisbon Strategy of economic and social renewal(Sustainable Development: What is the EU doing? (n.d.).). This strategy was commute to the dimensions of the sustainable development principle, the essence of the combination has potentials to curb the unnatural harm being caused to the environment resulting from fluctuations in the economy.

However, unsustainable trends continue several areas and therefore the efforts have to be compelled to be intense. One outcome united at the 2002 World Summit on property Development in the city was the necessity to line up national plans and programs on property consumption and production (10 Year Framework on SCP). The EU's contribution to the summit was printed in 2008, known as The property Consumption and Production and property Industrial Policy Action set up (SCP-SIP). It includes a series of proposals on SCP which will contribute to boost the environmental performance of a product and increase the demand for a lot of property product and production technologies. For a lot of info please visit the EU Commission's page on property Development.

Concerning the elaboration method of the property Development Goals (SDGs), the EC, together with his communication "A tight Life for all: from vision to collective action" printed in June 2014, tried to feed the work done at the United Nations level by the Open operating teams (OWG) sharing its priority areas. 
The European Commission welcome the new 2030 United Nations Agenda for property development in September 2015, and Vice-President Timmermans ensured implementation of the new Agenda and therefore the seventeen SDGs: "We area unit determined to implement the 2030 Agenda which can form our internal and external policies, making certain the EU plays its full half." The EEB believes that the ecu Commission has the right probability to gift a EU property Development Strategy with a concrete action set up for the implementation of the SDGs that shows it's understood the goals and therefore the have to be compelled to modification track.

\section{Suggestions towards Proper Implementation of the Sustainable Development Program}

The following vestige of game plan could be taken into consideration.

- Designing a newfangled strategy that could be centrally controlled by the union but could stand differentiated for different member countries as per their economic and environmental condition

- The inclusion of all the available resources and a reasonable consumption check on the resource consumption.

- The direct threats such as the Growing population and the concern of increasing consumption demands need to be eradicated.

- The fields relevant to the economy and environment should be taken into consideration.

\section{Conclusion}

The conclusion derived from the research gives clear indications about the interrelation of economics and environment, which stands as a key to the lock of environmental problems which is a relatable topic for the current generation may it be a connection to the global warming issue or the unsatisfied human needs it is all approachable to sustenance of development.

The spotlights are set to the implementation that has not been effective till date. This needs a careful evaluation for the points where the system lacks.

The critical process of evolution has not just brought changed humans but has evolved problems too which in return demands for a changed human behavior and a concept of satisfying needs has to be implemented.

\section{References}

Nakon, E. (2017, April 7). Hydropower Technology and Types of Hydroelectric Power Plants. Retrieved April 30, 2017, from http://www.renewableenergyworld.com/hydropower/tech.html

Daly, H. E. (1990). Toward some operational principles of sustainable development. Ecological Economics,2(1), 1-6. doi:10.1016/0921-8009(90)90010-r

Lélé, S. M. (1991). Sustainable development: A critical review. World Development,19(6), 607-621. doi:10.1016/0305-750x(91)90197-p

Pearce, D. (1988). Economics, equity, and sustainable development. Futures,20(6), 598-605. doi:10.1016/0016-3287(88)90002-x 
Sneddon, C., Howarth, R. B., \& Norgaard, R. B. (2006). Sustainable development in a post-Brundtland world. Ecological Economics,57(2), 253-268. doi:10.1016/j.ecolecon.2005.04.013

M. (1979). Assessment of geothermal resources of the United States, 1978. Geological Survey, Reston, VA (US A). Geologic Div. doi:10.2172/6870401

Telò, M. (n.d.). The Lisbon Strategy as a Global EU Strategy. Europe, Globalization and the Lisbon Agenda. doi: $10.4337 / 9781848446083.00026$

Seuring, S., \& Müller, M. (2008). From a literature review to a conceptual framework for sustainable supply chain management. Journal of Cleaner Production,16(15), 1699-1710. doi:10.1016/j.jclepro.2008.04.020

Clark, W. C. (2007). Sustainability Science: A room of its own. Proceedings of the National Academy of Sciences, 104(6), 1737-1738. doi:10.1073/pnas.0611291104

Agyeman, J., Bullard, R. D., \& Evans, B. (2006). Just sustainabilities: development in an unequal world. London: Earthscan.

Termorshuizen, J. W., \& Opdam, P. (2009). Landscape services as a bridge between landscape ecology and sustainable development. Landscape Ecology,24(8), 1037-1052. doi:10.1007/s10980-008-9314-8

Zarafshani, K., Sharafi, L., Azadi, H., \& Passel, S. V. (2016). Vulnerability Assessment Models to Drought: Toward a Conceptual Framework. Sustainability, 8(6), 588. doi:10.3390/su8060588

Markard, J., Raven, R., \& Truffer, B. (2012). Sustainability transitions: An emerging field of research and its prospects. Research Policy,41(6), 955-967. doi:10.1016/j.respol.2012.02.013

Ostrom, E. (2009). A General Framework for Analyzing Sustainability of Social-Ecological Systems. Science,325(5939), 419-422. doi:10.1126/science.1172133

Romolini, M., Bixler, R., \& Grove, J. (2016). A Social-Ecological Framework for Urban Stewardship Network Research to Promote Sustainable and Resilient Cities. Sustainability,8(10), 956. doi:10.3390/su8090956

Halcon, F. A. (n.d.). Environmental economics: A framework in analyzing problems in sustainability. PsycEXTRA Dataset. doi:10.1037/e610172012-007

Clark, W. C., Tomich, T. P., Noordwijk, M. V., Guston, D., Catacutan, D., Dickson, N. M., \& Mcnie, E. (2011). Boundary work for sustainable development: Natural resource management at the Consultative Group on International Agricultural Research (CGIAR). Proceedings of the National Academy of Sciences,113(17), 4615-4622. doi:10.1073/pnas.0900231108 